\title{
Long term planning of flood risks and processes of urbanistic development: the case of the Basilicata region (southern Italy)
}

\author{
M. Vita, A. Biscione, F. Bruno, M. Gerardi \& G. Lo Vecchio \\ River Basin Authority of Basilicata, Italy
}

\begin{abstract}
The River Basin Authority of Basilicata (AdB) is an interregional agency dealing with land protection and the planning of water resources. Its territory (which covers an area of about $9000 \mathrm{~km}^{2}$ in the south of Italy) is very abundant in environmental resources, but also very fragile and extremely rich in hydrogeological disturbances such as landslides and floods, due to its geological, geomorphological, hydrological and hydrogeological peculiarities. In this context the River Basin Hydrogeological Management Plan (PAI), which includes a Landslide Management Plan and a Flood Risk Plan, assumes a great importance since it is the regulatory instrument by which rules and actions dealing with land protection are planned and programmed.

From 2001 to the present, the Flood Risk Plan has been upgraded yearly, applying more and more meticulous hydrological and hydraulic mathematical models and using a gradually improved knowledge of the topography of the territory.

Within this process of continuous upgrading, new studies and researches have been started with the DIFA (Department of Environmental Engineering and Physics) of the University of Basilicata in order to classify different planning domains and ties taking into account the hydraulic depth and the flow velocity as suggested in the European Directive on the assessment and management of flood risks $(2007 / 60 / \mathrm{EC})$. In this paper the preliminary results of these studies are anticipated and the modern and innovative formulation of the Hydrogeological Safety Plan of the AdB, which tries to overcome its typical nature evolving from a set of rules and restraints into an instrument to suggest new ideas for a sustainable economic and urbanistic development, is explained.
\end{abstract}

Keywords: flood risk plan, directive 2007/60/ec, sustainable development. 


\section{The River Basin Authority of Basilicata: territory and main activities}

The River Basin Authority of Basilicata (AdB), established by the Basilicata Region with Regional Law n. 2/2001 in compliance with National Law 183/89 (now evolved in D.Lgs 152/2006), includes portions of the Basilicata Region territory and, to a lesser degree, of the Apulia and Calabria Regions.

In compliance with its institutive law, the AdB realizes study activities about the environment and its general risk conditions; it addresses, coordinates and controls the planning and programming activities, the realization of works in the field of land defence, water resources and environmental protection.

Its territory, located in the centre of southern Italy, covers an area of 8.830 square kilometres and includes six catchment basins, Bradano, Basento, Cavone, Agri, Sinni e Noce (Vita et al. [1]). All of these six rivers, with the exception of the Noce, flow into the Jonic Sea after having streamed in a NW-SE direction, through almost the entire region, in a parallel way. Distances between river mouths are of not more than six kilometres. This area is therefore very vulnerable to flood risk (fig. 1).

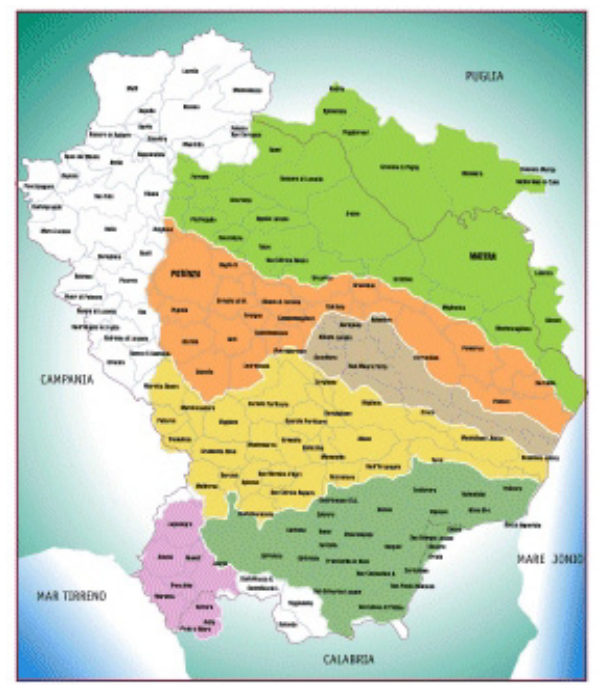

Figure 1: $\quad$ Territory of the River Basin Authority of Basilicata (AdB).

All of the territory of the AdB is very abundant in environmental resources, but also very fragile and extremely rich in hydrogeological disturbances such as landslides and floods, due to its geological, geomorphological, hydrological and hydrogeological peculiarities (fig. 2). In this scenario, activities of planning of the AdB become more and more important. 
The AdB started its activities seven years ago. During this period of time it has been improving and updating its programs yearly, mainly focusing on the River Basin Hydrogeological Management Plan (PAI).

The PAI represents the instrument to plan and program structural and nonstructural measures related to land protection with the aim of defending human life, but also economic activities and cultural/environmental goods, from landslides and flooding.
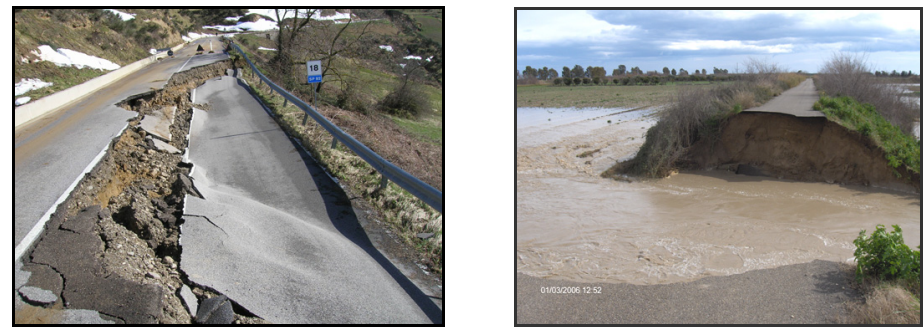

Figure 2: Examples of hydrogeological disturbances in the territory of the AdB.

It is divided in two sections: Flood Risk Plan and Landslide Management Plan. According to evolution of natural phenomena, to yearly acquired knowledge and information on hydrogeological existing disturbances, to mitigation works or actions, the two sections of the PAI have been updated seven times until today.

\section{The Flood Risk Plan}

The Flood Risk (FR) Plan is the key tool to prevent and manage territorial problems due to flooding risk. Starting from the knowledge of physical characteristics and from the analysis of flood hazard and risk, it specifies structural and non-structural measures (works/actions) useful to the regulation of the territory interested by floods.

The FR Plan is the regulative framework to which all authorizations and concessions about land uses have to be adapted and referred to. Its basic aims are:

- identification of river beds, floodplains and next areas that can be flooded in case of flow discharges with return period until 30 years (very high hydraulic hazard areas), with return period until 200 years (high hydraulic hazard areas) and with return period until 500 years (moderated hydraulic hazard areas);

- definition of management strategies and restraints to land use in flood risk areas, in order to reduce damages produced by human activities and natural phenomena, to preserve natural hydraulic dynamics of water surface bodies;

- identification of structural and non-structural actions/works to mitigate flooding risk. 
The Flood Risk Plan in force regards main rivers in the AdB territory (Bradano, Basento, Cavone, Agri, Sinni e Noce) but the purpose of the AdB is to extend it soon to principal tributaries.

Recently, aiming to improve and upgrade the topographic knowledge of territory, orthophotos and a Laser Scanning Digital Terrain Model were produced and elaborated.

The use of laser technology allowed obtaining a very detailed 3D-model of the ground in comparison with traditional DTM and this is of relevant importance in the Jonic coastal area which is a very flat lowland where obviously even very little variations in elevation can be determining to understand and describe natural phenomena like floods and coastal dynamics (Vita et al. [2]).

Topographical Laser surveys were conducted in 2006 by a group of Italian societies led by Geocart s.r.l. over an area of 400 square kilometres that includes a band of five kilometres from the coast toward inland and stripes, two km wide and 10 long, across the five rivers.

The system used is an integration of the laser scanner named "Topeye MKII", an Inertial Navigation System and a helicopter. This system allowed to acquire 4 point per square metre and therefore to describe with very high detail land morphology.

The laser used was a full wave form thus it was possible to classify surveyed data obtaining information on vegetation and anthropical structures (fig. 3).
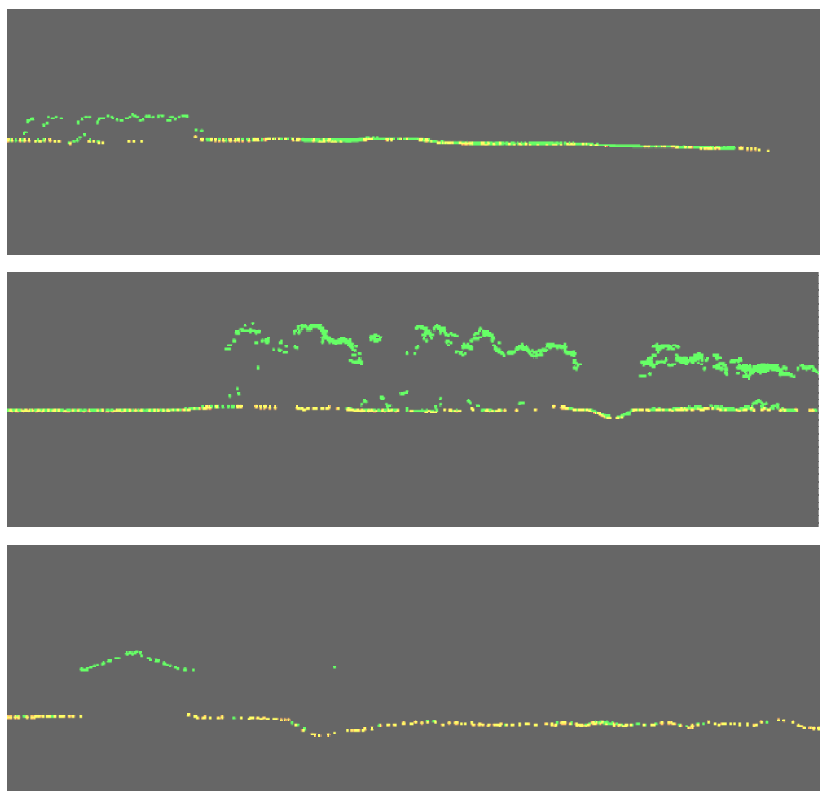

Figure 3: $\quad$ Examples of sections extracted from DTM. 


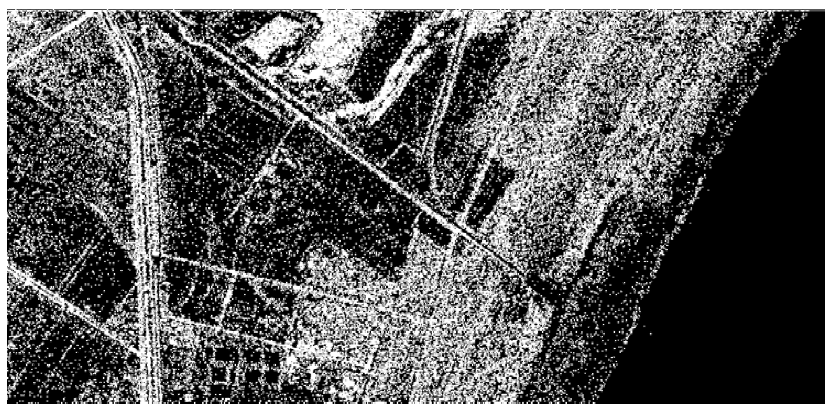

Figure 4: $\quad$ Model Key Point (MKP).

DTM was elaborated to facilitate its use creating a Model Key Point (MKP), which is a model with a lower density of points in more homogeneous areas and a higher density of points in zones with morphological variations (Guariglia et al. [3]).

Within the MKP all the discontinuities like irrigation or reclamation channels are extremely evident (fig. 4). Elaborations of DTM and MKP allow also very effective and useful representations of borders of flooding areas (fig. 5).

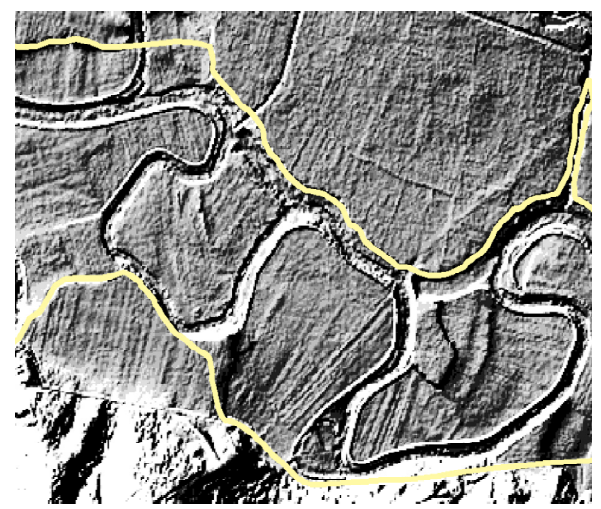

Figure 5: $\quad$ Borders of flooded areas represented on a hill-shade derived from DTM.

Laser DTM is the essential topographic base to improve methodologies to define Flood Risk areas from mono-dimensional modelling to two-dimensional modelling (Sole et al. [4]).

Using software like MIKE21 (Danish Hydraulic Institute) and FLO-2D (FLO-2D Software Inc) and with the assistance of the DIFA (Department of Environmental Engineering and Physics) of the University of Basilicata it is in progress a specific activity to define not only the exact limits of flooding areas but also water depths and flow velocities in order to better differentiate rules and restraints within flooded areas. 
Preliminary applications of 2D-models have, first of all, shown that under unsteady flow conditions it is extremely important to define with accuracy the flood hydrogram and not only the peak of flow discharge since hydrograms are directly related to water volumes to be distributed over floodplains and lowland.

Besides, comparison between results obtained with mono-dimensional models (on which is based the in force Flood Risk Plan) (Giosa [5]) showed that 2Dmodels generally lead to lower values of water depths over wider flooded areas (fig. 6).
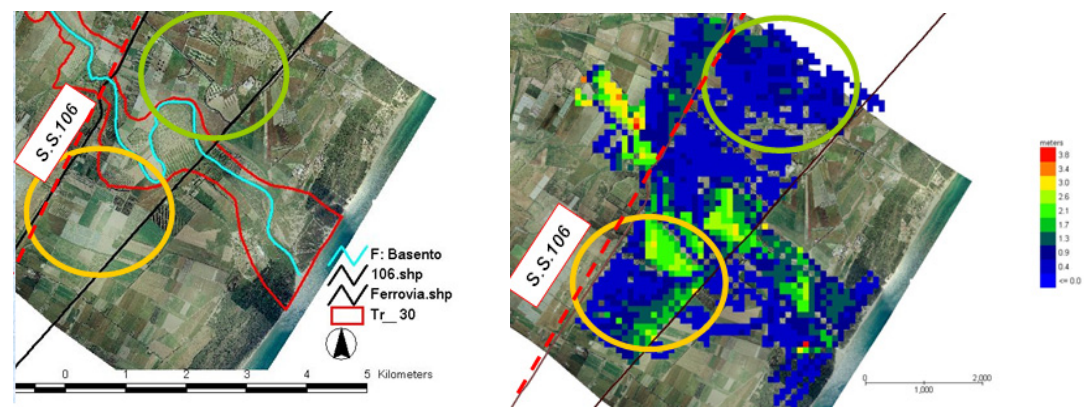

Figure 6: Comparison between flood risk areas with $\operatorname{Tr}=30$ years obtained by applying mono-dimensional models to the first results of the application of two-dimensional models.

This scenario emphasizes the significance of making a differentiation in strategies and restraints to land use in relation to water levels and that in order to avoid an extension of limits and ties not related to real hazards.

This important concept is underlined also in the Directive 2007/60/EC on the assessment and management of flood risks that includes "water depth" and "flow velocity" among needed elements to define floods scenarios with low, medium or high probability, functional to define Flood Hazard Maps.

Hence, the evolution of the PAI of the AdB of Basilicata is already going into the direction indicated by the European Directive, this will facilitate to comply with its transposition in Italian laws. Furthermore Italian legislation on land protection is far more aged, it started in 1989, that is the law of institution of Basin Authorities thus actions to be done after the transposition of the Directive 2007/60/EC will mainly consists in adapting existing procedures.

As a matter of fact no difficulties can be forecasted to apply all what regards Hazards Map and Flood Risk Map while some kind of problem could be encountered when defining objectives for Flood Risk Management Plans since in Italian Law, Flood Management Plans are intended to be "long term" planning acts aiming to provide a potential economic and urbanistic development compatible with flood hazards. Therefore activity of Basin Authorities is much more concentrated in defining rules and restraints than on flood forecasting, early warning systems and so on. These last activities are accomplished by Civil Protection structures. 
According to Directive on the assessment and management of flood risks, all the aspects related to floods should be afforded within the Flood Risk Management Plans consequently its complete definition in Italy would imply the cooperation of several institutions. This will be an important theme to be afforded by Italian legislator in drawing up the transpositions measures of the Directive.

\section{An integrated approach between territorial development processes and flood risk planning}

In recent years the $\mathrm{AdB}$ has started to undertake its activity developing a different way to consider the River Basin Hydrogeological Management Plan not only as a set of rules and restraints that ties and hinders the territorial development but also as an instrument able to give suggestions and indications of environmental protection to be integrated in urban and territorial planning and within political choices for the territorial and economic development.

Two study cases going in this direction are following briefly illustrated.

\subsection{Integration between the territorial plan of the Basento river mouth area and the flood risk plan}

The study case presented regards an area of about 700 hectares across the Basento river mouth, one of the most important rivers in the AdB territory that flows into the Jonic Sea.

The Jonic coastal area during last decades was interested by an intense economic transformation related to sectors of intensive agriculture and tourism. This happens also to the area more proximal to Basento River.

In this context river bed and floodplain once covered with luxuriant vegetation was gradually reduced to a narrow stripe unable to completely accomplish its ecological function.

In this area the Flood Risk Plan of the AdB has demarcated flood risk areas and it has defined rules to avoid transformations incompatible with hazard conditions. Nevertheless FR Plan is not only based on "defensive" criteria but also on "open" once. Since it suggests the possibility, under specific conditions, to use areas proximal to river for recreational and sporting activities and, in areas with moderated hydraulic hazard, also the possibility to realize interventions and works that do not imply realization of new building volumes and that do not create obstacles to flood discharge.

The Territorial Plan of Basento river mouth that at the moment is in progress, has gathered the "open" approach of the FR Plan and has considered the river as a basic invariant, proposing the realization of a River Park as central element of the Plan with recreational intent but also with the aim of recreating an adequate ecologic function (Vita et al. [6]).

In order to gratify or at least not to put at disadvantage owners of land near the river to be destined to the River Park, the principle of territorial equalization 
was proposed and accepted by the Authority of Basin. This way the building volumes up to owners of land in the park are transferred in other areas more fit to the realization of new building volumes while areas in the park become obviously public.

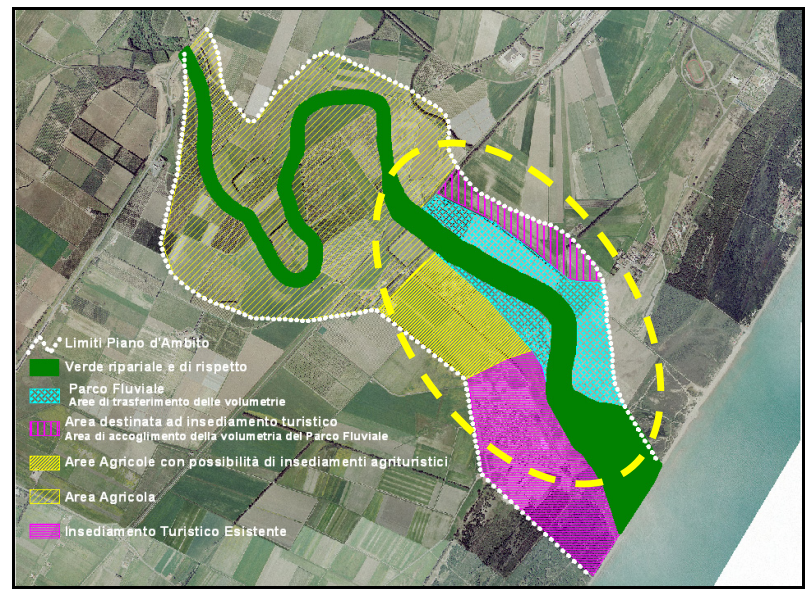

Figure 7: $\quad$ Territorial Plan of the Basento river mouth area.

\subsection{Park of the Noce River: recovery and upgrading of an area with high environmental and touristic value}

During 2007 the AdB participated in compiling an Integrated Program for the environmental recovering and for the touristic development of the catchment basin of Noce River (Di Fazio et al. [7]).

Partners of the program were the Group of Local Action - Allba, promoter of economic enterprises for local development established within the European Program named "Leader Plus", and the Mountain Community of Lagonegrese, a public organization dealing with social and economic programming and planning in mountain territories of the southern area of Basilicata region.

Activity performed until today allowed drawing up a Preliminary Plan and Program of basic interventions while a second phase is now in progress to define in details actions and works and to individualise the needed economic resources (regional, nation or communitarian).

The plan, elaborated by means of Swot Analysis and Logical Framework Approach, attributes a central role to the involvement of local public institutions and possible private partners like entrepreneurs in the fields of agriculture, craftsmanship, leisure and sports, aiming to reach a shared vision of the territory based on the importance and value of natural resources to be seen as occasion of local development.

The Program individualise actions, interventions, activities intended to protect natural and environmental aspects of river area, to recreate its historical identity, 
to remove critical situations due to human activities and to give value to the environmental, historical and cultural interactions between populations and the river. It has the scope to address local activities towards new economical activities environmentally sustainable and well integrated with local cultural traditions.
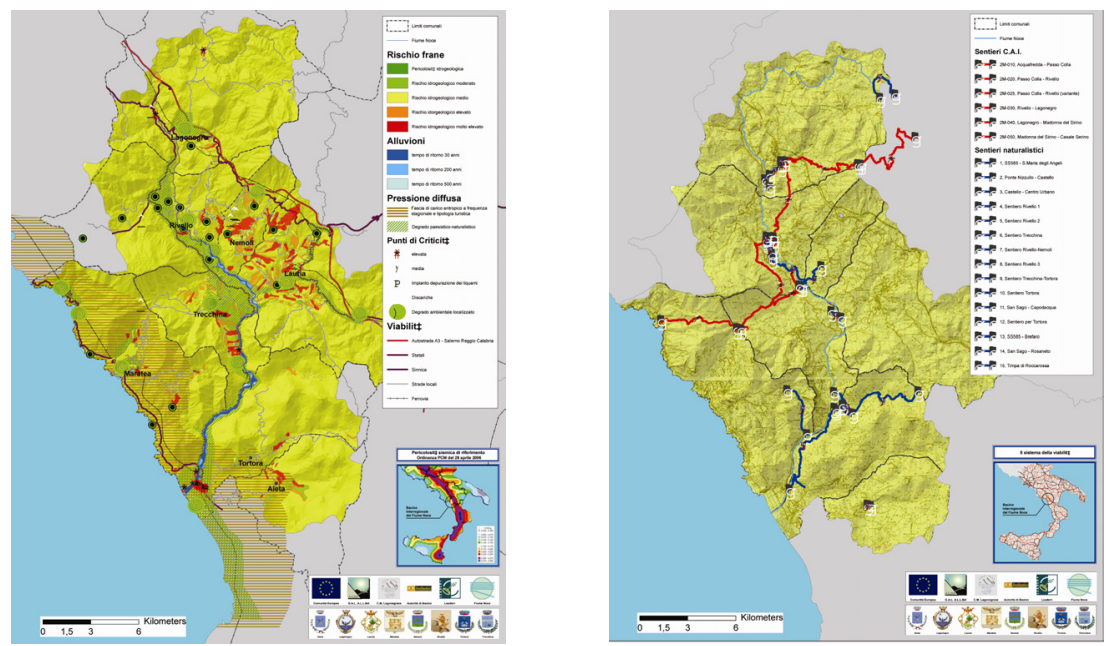

Figure 8: Analysis of anthropical pressures and of the critical situations plan of naturalistic paths.

\section{Conclusions}

In the present paper it was presented the approach of the River Basin Authority of Basilicata to Flood Risk planning and it were illustrated the improvements in progress to define, in lowland areas, flood hazard maps differentiated on the basis of values of water depths.

Then, two examples were briefly discussed: the Territorial Plan of Basento river mouth area and the Project of the Park of Noce River. The River Basin Authority of Basilicata participated in these projects giving suggestions aiming to address the local need for economic development towards forms of development compatible with prevention from flood hazard and respectful of environment.

\section{References}

[1] Vita, M., Segreteria Tecnica AdB, Piano Stralcio per la Difesa dal Rischio Idrogeologico, Vol. 2, ed. Suolo e Acqua, AdB della Basilicata, 2006. Also Online: http://www.adb.basilicata.it/adb/pubblicazioni/vol2.asp. 
[2] Vita, M., Bulfaro, M., Cavuoti, C., Magliaro, S., Biscione, A., Valanzano, A., Evoluzione del litorale Jonico lucano tra le foci dei fiumi Sinni e Bradano. Ambiente e Territorio, ed. Maggioli, Vol. 3, 2007.

[3] Guariglia, A. Rilievo e analisi di dati multi-sorgente per il monitoraggio la valutazione dell'evoluzione costiera: il caso del litorale ionico lucano, Degree Thesis. Engineering Faculty, University of Basilicata, Potenza, 2006

[4] Sole, A., Giosa, L., Copertino, V., Risk flood areas, a study case: Basilicata Region. River Basin Management IV, ed. C.A. Brebbia, Katsifarakis, WIT Transactions on Ecology and the Environment, Vol 104, 2007.

[5] Giosa, L., Tecnologia laser-scan e modelli idraulici per la valutazione del rischio di inondazione nelle pianure costiere, $\mathrm{PhD}$ Thesis, $\mathrm{PhD}$ Course in Hydraulic Engineering, University of Basilicata, University of Calabria, University of Salento, Politechnic of Bari, 2007.

[6] Vita, M., Biscione, A., Cerverizzo, G., Gerardi, M., Lo Vecchio, G., Vasta, G., Piano delle fasce fluviali e processi di trasformazione del territorio. L'acqua, ed. Associazione Idrotecnica Italiana, Vol. 3, 2007.

[7] Di Fazio, G., Biscione, A., Bruno, F., Gerardi, M., AdB della Basilicata, Gal Allba, Comunità Montana del Lagonegrese, 2007. Online: http:// www.adb.basilicata.it/adb/studi/noce.asp 